\title{
Trying to meet the demands in organ transplantation
}

\author{
Christopher Nguan, MD, FRCSC
}

Assistant Professor, Department of Urologic Sciences, University of British Columbia/Vancouver General Hospital, Vancouver, BC

See related article on page 448.

Cite as: Can Urol Assoc J 2012;6(6):453-4. http://dx.doi.org/10.5489/cuaj.12339

S ince the dawn of kidney transplantation, there has always been the inherent tension between lack of adequate organ supply versus demand for those valuable organs. Transplant programs are constantly innovating in an effort to identify, validate and implement organ donor strategies to increase organ supply and get their patients transplanted and free from dialysis long term. By far, the largest worldwide experience has been with the use of kidneys from donors following neurological determination of death (NDD, brain death). The use of so-called NDD expanded criteria donors (ECD) who harbour risk factors predicting satisfactory, but less than ideal long-term outcomes, has taken off over the past two decades; even further down the spectrum of perceived risk is donation after cardiac death (DCD) transplants, in which organs are procured for transplantation after the removal of cardiocirculatory support in appropriate patients. DCD transplants now account for about $10 \%$ of all transplants performed in Canada, ${ }^{1}$ and appears to be a relatively untapped source of donor organs. Contemporary literature suggests DCD transplants incur worse early graft outcomes in favour of excellent long-term graft and patient survival. ${ }^{2-6}$

In their article, Moser and colleagues review what is arguably Canada's longest single-centre experience with this high-risk transplant. ${ }^{7}$ This group demonstrates an evolving DCD program, with improvements in procedural tasks during procurement and subsequent reduction in warm ischemic times. Machine pulsatile perfusion efforts were recruited with increasing frequency as the program developed with what appears to be an impact on improving early graft function, although rates of delayed graft function (DGF; need for dialysis in the first week post-transplantation) did not change significantly (59\%-71\%). Long-term follow-up of patient or graft survival was not reported in this study, but creatinine clearance at one year post-transplant was excellent $(66.7 \mathrm{~mL} / \mathrm{min}$ median). Importantly, the original goal of initiating this program was to increase donor organ availability for transplant; to this end, they have succeeded by increasing total numbers of kidney transplants by $25 \%$.

End-stage renal disease (ESRD) is often the final pathology for a variety of chronic disease conditions, such as hypertension, diabetes and metabolic syndrome. With epidemic increases in these contributory chronic conditions, an aging population and a demand by that population segment for optimum health care, ESRD is on the rise and renal replacement strategies, such as transplantation, will have to follow suit to meet demand. While NDD donors will continue to be recruited by transplant programs, they have shown to be relatively static in number and cannot meet current demand for organ supply, nor ongoing increases. Therefore, it is crucial that ongoing dialogues are maintained to diversify new sources of potential donors for transplantation. It wasn't long ago that DCD donors were considered too risky, unethical, opportunistic, or morally objectionable. While there continues to be debate on the use of DCD donors, ${ }^{8}$ programs will continue to push the limits of what may be socially acceptable within the limits of what is medically and ethically responsible in the determination of organ donor eligibility.

Competing interests: None declared.

This paper has been peer-reviewed.

\section{References}

1. Analysis in Brief: Organ Donor Activity in Canada, 1999 to 2008. Canadian Institute for Health Information, Ottawa, Canada. 2009. 
2. Joffe A, Carcillo J, Anton N, et al. Donation after cardiocirculatory death: a call for a moratorium pending full public disclosure and fully informed consent. Philos Ethics Humanit Med 2011;6:17.

3. Arnold RM, Youngner SJ, eds. Ethical, Psychosocial, and Public Policy Implications of Procuring Organs from Non-Heart-Beating Cadavers. Kennedy Institute of Ethics Journal 1993;3(2, theme issue). http:// muse.jhu.edu/journals/kennedy_institute_of_ethics_journal/toc/ken.3.2.html (Accessed December 6, 2012).

4. Proposal to Update and Clarify Language in the DCD Model Elements. Affected/ Proposed Bylaw. Organ Procurement Organization (OPO) and Organ Availability (OAC) Committees. http://optn.transplant.hrsa. gov/PublicComment/pubcommentPropSub_283.pdf (Accessed December 6, 2012).

5. Herdman R, Potts JT. Non-Heart-Beating Organ Transplantation: Medical and Ethical Issues in Procurement. Washington, DC: National Academy Press; 1997. http://www.nap.edu/openbook.php? record_ id=6036 (Accessed December 6, 2012).

6. Committee on Non-Heart-Beating Transplantation II: The Scientific and Ethical Basis for Practice and Protocols. Non-Heart-Beating Organ Transplantation: Practice and Protocols. Washington, DC: National Academy Press; 2000. http://www.nap.edu/openbook.php?isbn=0309066417 (Accessed December 6, 2012).
7. Moser M, Sharpe M, Weernink C, et al. Five-year experience with Donation after Cardiac Death kidney transplantation in a Canadian transplant program: Factors affecting outcomes. Can Urol Assoc J 2012:6:448-52. http://dx.doi.org/10.5489/cuaj.12104

8. President's Council on Bioethics. Controversies in the Determination of Death: A White Paper by the President's Council on Bioethics. Washington, DC;2009. http://bioethics.georgetown.edu/pcbe/ reports/death/index.html (Accessed December 6, 2012).

Correspondence: Dr. Chris Nguan, Department of Urologic Sciences, University of British Columbia/ Vancouver General Hospital, 6th Fl, 2775 Laurel St, Vancouver, BC V5Z 1M9; fax: 604-875-5604; info@nguan.ca 